\title{
Analysis on the reform of AutoCAD course in Higher Vocational interior design
}

\author{
Jia Luo \\ Urban vocational college of Sichuan, Sichuan,Chengdu,610066
}

\begin{abstract}
KEYWORD: Higher vocational; interior design; AutoCAD; teaching reform
ABSTRACT: With the development of rapid expansion of the interior design industry, market demand of interior designers are greatly increased, causing the school running scale of Higher Vocational Colleges rapidly expanding in such a big environment, higher vocational colleges how to cultivate students professional interior design, so as to adapt to the market, has become the urgent matter of the moment. Taking AutoCAD course as an example, for interior design major in Higher Vocational Colleges of AutoCAD, problems existing in the operation process of CAD teaching current situation and student, according to the higher vocational teaching reform spirit, adapt to the higher vocational talents training needs, strengthen the study and other problems related to teaching, in the improvement of teaching methods, strengthen the practice link, pay attention to the links computer training and theory, combined with the actual situation in formulating the teaching plan, operating speed training of AutoCAD in higher vocational colleges.
\end{abstract}

\section{Introduction}

The rapid development of China's economy, the professional interior design is also growing rapidly, the size and the number of increase for the development of art education in China has contributed to, but along with the competition of graduates' employment pressure is more and more big, higher vocational colleges such as

Fruit also continues to use the previous course teaching mode, then trained students find it difficult to adapt to the social needs. Therefore, higher vocational colleges should establish a new talents training target, to highlight the "skills, higher vocational colleges teaching theory and enterprise practice organic melting as a whole, the training of students to adapt to the social. Therefore, in order to meet the teaching in higher vocational education, accelerate China's high-quality shortage. Skilled talents training pace, higher vocational education must to employment oriented, to market demand to develop "orders of \$training objectives, should pay attention to the professional skills of students. The cultivation of practical ability, which requires students to master the use of computer aided design software. AutoCAD is a professional interior design is a important basic technology course in traditional teaching, this kind of computer software courses only requires students to master the software operation.

\section{The current situation of AutoCAD teaching in Higher Vocational interior design majors and the problems in the process of CAD operation}

Did not deal with the role of AutoCAD, a connecting link between the preceding and the following, interrupted and before the subsequent course of AutoCAD contact is a tool to solve practical problems, which determines the it and other basic knowledge in the teaching of the past, indoor drawing and AutoCAD is the separation of teaching, which is a simply the mapping of content and AutoCAD content into, the main arrangement is according to the traditional custom, the first indoor drawing teaching and students practice using manual drawing, indoor mapping content all after the end to a term introduced AutoCAD software the deficiencies of this teaching method is mainly in the following three points:

One is easy to cause the students to interior drawing and AutoCAD drawing as two different theoretical system of the curriculum, while ignoring the AutoCAD drawing is a drawing method and manual drawing, just use a different tool only, and also can be used in with solid theoretical basis for the indoor map drawing method; the two is due to the basic theory of interior drawing not related to timely and effective combination of AutoCAD, students in practice, often not in 
accordance with the basic theory and rules drawing, the drawing does not conform to GB "\$three is required; two contents disjointed, students cannot in practice and hand exercises combining content, generally a single command exercises, use various orders of understanding is not deep, students have no sense of achievement, learning interest is not high in the teaching plans is the course as a whole a system to consider, therefore in the process of teaching should be taken into account in the cohesion and coherence between them.

\section{The curriculum theory and curriculum practice}

In the past, the teachers always pay more attention to the theory teaching, and the content analysis of the class is clear. At present, CAD teaching exists such problems, in the theoretical teaching, some vague concepts and practice content is very different, the lack of specific command pertinence and practicability, students learn to accept, so dull as ditch water Learning often uninterested, but the actual situation is to draw a simple content the steps may require dozens of hundreds of students, could not remember so many contents in the classroom just 3 minutes, even then remember some key steps, but soon after if not to practice will soon forget \# and in the process of practical teaching, not to implement the theory the principle, which makes the students only know the table and not in \# because teachers did not handle the relationship between theory teaching and practice teaching, the teaching effect of \#H0e learning is actually how will use this platform in the computer! It is familiar with, theory teaching should create good conditions for the students in practice, playing well.

\section{No according to different levels of students formulate specific teaching plan}

In recent years, higher vocational colleges overall qualities of the students showed a rising trend, but inevitably is most students cultural foundation is uneven, in the same teaching plan, some students comprehension ability, speaking to understand, will, while another small part of the students theoretical knowledge did not understand not to mention exercises on the machine operation, more from poor areas before they enter a computer connected to the no operation, On the keyboard and mouse operation is not skilled, this part of the students in the course of learning difficulties encountered in the. Over time, this little part of the students in the process of learning CAD will become more and more interest, resulting in the final abandoned.

\section{The students' problems in the process of AutoCAD operation}

Construction drawing not standardized the majority of students the basic drawing skills, the final construction drawings does not conform to the drawing standard drawing is not standard there are the following reasons: now the national Ministry of construction has no set a standard of interior design drawing specifications. Most of the interior design of the graph specification is applied architectural drawing and furniture drawing national standard so ultimately lead to various decoration companies have their own drawing specifications. Mainly according to the traditional teaching habits of the arrangement, the first interior decoration drawing teaching, such as after the end of the building interior decoration drawing all the AutoCAD drawing software use such teaching methods easily lead to students not in a timely manner to indoor decoration drawing lessons and AutoCAD integration, so students in computer graphics, often do not according to the mapping of the basic theory and basic provisions, the drawings does not meet the national standard requirements.

CAD operation speed is slow at present most of the students of AutoCAD Application just to stay in, but slow \# for businesses time to is profit, vocational just graduated students can independently complete the entire scheme, only by the draftsman start. Therefore, higher vocational college students on the application of computer drawing speed. Students to the slow speed of operation of the reason mainly has following several aspects: previous teaching, teachers' teaching requires a low, do not attach importance to the training of students in the operating speed of some teachers lack of social practice, not skilled in operating CAD software students drawing with the mouse in the graphics interface selection tool based, didn't get in the habit of using the highefficient enter the health habits. 


\section{To meet the needs of higher vocational education and improve teaching method}

First, the teaching content of plug-in insertion type teaching method is teaching H0e drawing content, appropriate interior design drawing specifications into each section for detailed instruction, using this method is to enable students to understand the computer aided drawing and manual drawing only two different drawing means, is no longer on the computer aided drawing have a magical and profound feeling, thus increasing the confidence of students; second, project case introduction teaching method is case teaching method, which is the whole course of one to two project introduction, then each project is decomposed into a sub task, with explanation in the classroom to do, from easy to difficult, for example: draw a set of interior design drawings as a project; plan ceiling plan elevation as a sub project; so every class to make full use of case analysis of anatomy, to palm by example making

Use the holding command, to improve students' understanding of ability, do the case selection to infer other things from one fact, targeted, to meet the professional characteristics, reflect the current reality, and can improve the students' learning interest and achievement strengthen practice, emphasizing on training and theory, combined with the actual situation of making teaching plan in theory the class each student as a clear hands-on learning task, asking them to finish the operation requirements, and do homework work with multimedia interactive teaching mode of teacher professors and students of synchronous operation in the teaching form, this form of learning while operating, the teaching effect is ideal or in the theoretical teaching, operating scheduled later in the day, the latest should not exceed 10 days, otherwise the students grasp the knowledge points some will forget in the arrangement of operating tasks, pay attention to the knowledge point to review previously learned that, from the shallower to the deeper from easy to difficult learning step by step step students master corresponding skills in fun.

For students who do not have their own computer, the teacher should actively and school authorities negotiation, for students to create a favorable condition of the machine AutoCAD application requires not only with good use of, should reflect the drawing speed, so the teaching process should emphasize fast key, unifies social reality in the period after class, teach students how to customize the shortcut key, to pave the way for the practical application in the future.

The author through years of teaching, found the problem and after analysis on the current situation of students learning and teaching, put forward some ideas for reform, aims to initiate, make more colleagues recognize and attach importance to the problems have been neglected in the teaching of this course, believe that through further reform and construction of the course and to promote the construction of other courses and professional construction Discipline construction, and comprehensively promote the education innovation and implementation of quality education, deepen the reform of education and teaching, improve the quality of personnel training, enhance the comprehensive strength and competitiveness has important significance I have to participate in the research on the reform of the teaching of this course, making better interior design professional development.

\section{Reference}

[1] Sun Jian. Problems and Countermeasures of Higher Vocational College Project Teaching Reform [J]. Reform in Education, 2015,157(3): 105-107.

[2] Qing Wei. The application of CAD technology in the teaching of mechanical design in Higher Vocational Colleges[J]. Science and tehnology vision, 2015, 185-186.

[3] Tan Ming. Research on the design method of CAD in Higher Vocational Colleges[J]. Read and write periodical, 2015,12(5): 68 . 